\title{
Applications of USP apparatus 3 in assessing the in vitro release of solid oral dosage forms
}

\author{
Bianca Ramos Pezzini', Michele Georges Issa ${ }^{2}$, Marcelo Dutra Duque², Humberto Gomes Ferraz ${ }^{2, *}$
}

${ }^{1}$ Pharmacy Department, Joinville Regional University, Santa Catarina, SC, Brazil, ${ }^{2}$ Pharmacy Department, Faculty of

Pharmaceutical Sciences, University of São Paulo, São Paulo, SP, Brazil

\begin{abstract}
USP Apparatus 3 (reciprocating cylinder) is a very versatile device for the in vitro assessment of release characteristics of solid oral dosage forms, because it enables the product to be subjected to different dissolution media and agitation speeds in a single run. In this paper, a brief history and a description of this system are presented, along with its applications in the development of immediate and modified release products and in the simulation of fasted and fed states using biorelevant media. Furthermore, a comparison is made with the basket and paddle apparatus, especially highlighting the superior hydrodynamics of USP apparatus 3, since the results are not sensitive to factors such as the presence of sample collection probes or air bubbles in the dissolution medium.
\end{abstract}

Uniterms: Solid dosage forms/in vitro release. Solid dosage forms/dissolution. Apparatus 3/use/evaluation of solid dosage forms. Reciprocating cylinders.

USP aparato 3 (cilindros recíprocos) é um equipamento bastante versátil para a avaliação das características de liberação in vitro de formas farmacêuticas sólidas orais, pois permite que o produto seja submetido a diferentes meios de dissolução e condições de agitação, em um único ensaio. Neste trabalho, são apresentados um breve histórico e a descrição desse sistema, suas aplicações no desenvolvimento de produtos de liberação imediata e modificada, assim como sua utilização na simulação dos estados não alimentado e alimentado com o emprego de meios biorrelevantes. Além disso, uma comparação é estabelecida com o cesto e a pá, com destaque para a hidrodinâmica superior do USP aparato 3, que faz com que os resultados não sejam influenciados por fatores como o uso de sondas de coleta de amostras ou presença de bolhas de ar no meio de dissolução.

Unitermos: Formas farmacêuticas sólidas/liberação in vitro. Formas farmacêuticas sólidas/dissolução. USP Aparato 3/uso/avaliação de formas farmacêuticas sólidas. Cilindros recíprocos.

\section{INTRODUCTION}

Bioavailability and, consequently, the therapeutic effects of orally-administered medicinal products depend on the dissolution of the active ingredient in gastrointestinal fluids, as well as its permeation through the membrane of the luminal mucosa. Where the absorption process is rapid, dissolution may be the stage that controls the introduction of the drug into the bloodstream (Amidon et al., 1995; Emami, 2006). This, in

\footnotetext{
*Correspondence: H. G. Ferraz. Pharmacy Department. Faculty of Pharmaceutical Sciences. University of São Paulo. Rua do Lago, 250 - Prédio SemiIndustrial - Térreo - Cidade Universitária - Butantã - 05508-080 - São Paulo - SP, Brazil. E-mail: sferraz@usp.br
}

turn, led to universal recognition that the dissolution test is indispensable in the development, quality assurance and post-marketing authorization modifications of solid oral dosage forms (Dokoumetzidis, Macheras, 2006; Azarmi, Roa, Löbenberg, 2007).

Furthermore, in the context of the Biopharmaceutics Classification System (BCS), proposed by Amidon et al. (1995), the dissolution test, together with bioavailability studies, has become an essential tool for the establishment of an in vitro-in vivo correlation (IVIVC) (FDA, 2000).

With regards to the apparatuses used in the dissolution test, the basket apparatus (USP apparatus 1) was the first to be adopted by the U.S. Pharmacopeia in 1970, while the paddle apparatus (USP apparatus 2) was recognized in 1978, as the result of ongoing developments 
in the area and a growing interest in matters related to dissolution (Dokoumetzidis, Macheras, 2006).

However, research in the field of modified release dosage forms has indicated that, in order to obtain a correlation between in vitro dissolution results and the bioavailability of these products (in vitro-in vivo correlation), it would be essential for the $\mathrm{pH}$, composition, ionic strength, viscosity and agitation speed of the medium to be sequentially altered during the dissolution test, thus simulating passage of the product through the gastrointestinal tract. With the purpose of addressing this issue, a group of researchers from the University of London, headed by Professor A.H. Beckett, developed the reciprocating cylinder method (Borst, Ugwu, Beckett, 1997; Yu, Wang, Hussain, 2002).

In the 1970s, Professor Beckett's team used the rotating bottle method in order to assess the dissolution profiles of extended-release products, which presented important advantages over the basket and paddle apparatuses, especially with regards to hydrodynamics and the possibility of using the $\mathrm{pH}$ gradient. However, the method was extremely labor-intensive and there were limitations with regards to automatization of the system (Borst, Ugwu, Beckett, 1997; Jorgensen, Bhagwat, 1998).

Thus, the reciprocating cylinder apparatus was conceived, with a design based on the capsule and tablet disintegration device, associating the hydrodynamics of the rotating bottle method with the facility for exposing the dosage form to different dissolution media and agitation speeds, in a device that could be automated. This proposal was incorporated into the U.S. Pharmacopeia in 1991 (Yu, Wang, Hussain, 2002) as USP apparatus 3, making it an alternative to USP apparatuses 1 and 2 for the assessment of dissolution characteristics of products that consist of solid oral modified-release dosage forms (Borst, Ugwu, Beckett, 1997; Krämer, Grady, Gajendran, 2005; Wang, Fotaki, Mao, 2009).

Accordingly, considering the importance of assessing the dissolution of solid oral modified-release dosage forms with the reciprocating cylinder, the purpose of this study is to discuss the applications of this apparatus on the assessment of in vitro release of solid oral dosage forms and to establish a comparison between the aforementioned system and the basket and paddle apparatuses.

\section{DESCRIPTION OF RECIPROCATING CYLIN- DER APPARATUS}

The main components of the reciprocating cylinder apparatus are internal cylinders, external cylinders, metallic agitation rods and the heating bath. Each unit of the dosage form is inserted into an internal cylinder, consisting of a glass tube closed at both ends with plastic caps containing a screen, which is made of nylon or stainless steel (Figure 1a).

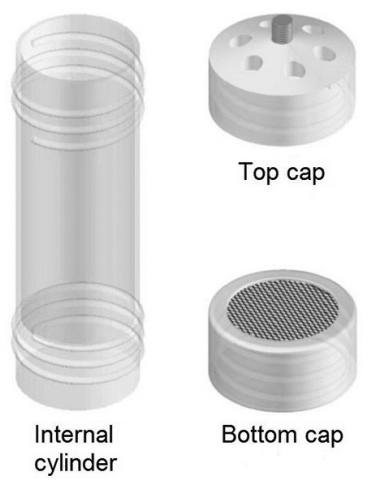

(a)

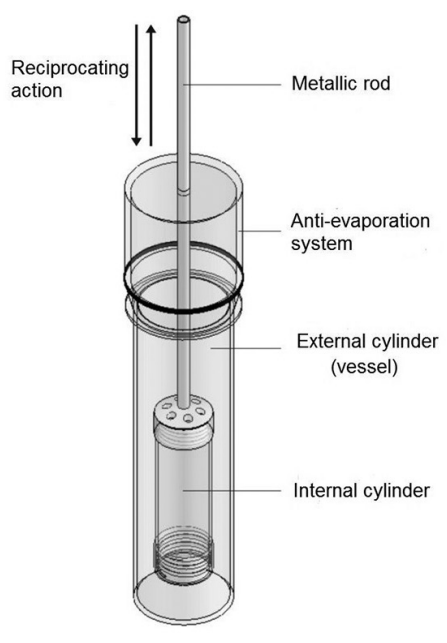

(b)
FIGURE 1 - Reciprocating cylinder apparatus: (a) Internal cylinder and its top and bottom caps (b) illustration of the internal cylinder coupled to the rod inside the external cylinder (vessel).

The internal cylinders are coupled to metallic rods that undertake the immersion and emersion movements (reciprocating action) within the dissolution vessel, which is called the external cylinder. This vessel is very different from the one used for the basket and paddle methods because, besides its distinctive cylindrical format and flat bottoms, it has a capacity of only $300 \mathrm{~mL}$. Besides the standard $300 \mathrm{~mL}$ vessels, other vessels for specific applications are also available, with $100 \mathrm{~mL}$ and 1,000 mL capacities. An anti-evaporation system is deployed over the vessels in order to avoid alterations in the volumes of the dissolution medium during the assay, as illustrated in Figure 1b.

The heating bath contains dissolution vessels arranged in lines; temperature of the medium is maintained at $37^{\circ} \mathrm{C}$. Each horizontal line consists of 7 vessels, 6 for the product and the seventh may be used for the standard solution, in systems in which the quantification stage is automated, or even to contain the replacement medium, in the event that this procedure is adopted after the collection of samples.

The internal cylinders remain in each line of vessels, in reciprocal movement, for pre-programmed times and intensities (dips per minute or "dpm") in the 
apparatus. During emersion, the agitation system rises until the screen in the lower cover touches the dosage form, which separates from the screen and floats freely in the dissolution medium when the stirring system activates. After the programmed period, the rods rise until the internal cylinders are positioned over the vessels, where they remain for a pre-established timeframe so that the dissolution medium can drain. Then the rods move to the following line, submerging again and the reciprocating actions begin anew.

The system contains six lines of vessels, but if a larger volume of dissolution medium is necessary to ensure sink conditions, it may be programmed so that, after the cylinders move along the sixth line, they return to the first, where the medium must be replaced.

The time the internal cylinders remain in each line of vessels as well as the $\mathrm{pH}$, the composition, ionic strength and agitation speed of the dissolution medium may be selected, according to physiological conditions and, accordingly, it is possible to simulate the passage of the product through the gastrointestinal (GI) tract.

Samples are collected throughout the test in order to quantify the drug released and the dissolution profiles are traced after calculating the cumulative percentage of drug dissolved. Thus, the amount of drug released from the dosage form at the end of the test will correspond to the sum of percentages quantified in all the vessels covered.

\section{APPLICATIONS FOR MODIFIED-RELEASE SOLID ORAL DOSAGE FORMS}

Modified-release dosage forms offer therapeutic advantages over conventional release mechanisms due to the use of advanced technologies and excipients with special characteristics, and they are thus capable of generating a specific dissolution profile. However, the complexity that they present and the necessity for in vivo performance to be predictable and reproducible means development becomes more complex (Kumar, Domb, 2004).

One issue to be considered is the time that these products remain in the GI tract, which is greater compared to the immediate-release forms, since the latter undergo rapid disaggregation when they come in contact with an aqueous medium. As a result of the greater exposure time, the performance of extended-release products is more susceptible to the mechanical forces and physicochemical conditions of the luminal environment (Dokoumetzidis, Macheras, 2006). Since the reciprocating cylinder method enables these conditions to be simulated, it is reasonable to suppose that this apparatus is more efficient than the basket and paddle methods in predicting the in vivo performance of extended-release dosage forms (Krämer, Grady, Gajendran, 2005; Pezzini, Ferraz, 2009).

One fundamental condition for the development of dissolution methodologies is the suitable selection of the $\mathrm{pH}$ of the medium, since this affects drug solubility. These methodologies involve mostly weak acids or bases (Klein et al., 2005). When modified-release products are tested in apparatus 3 , it is possible to simulate the different environments to which the dosage forms are subject when they pass through the GI tract (Figure 2). These conditions can be assessed by employing different buffer solutions with or without surfactants (Pezzini, Ferraz, 2009; Ribeiro, Ferreira, Veiga, 2005).

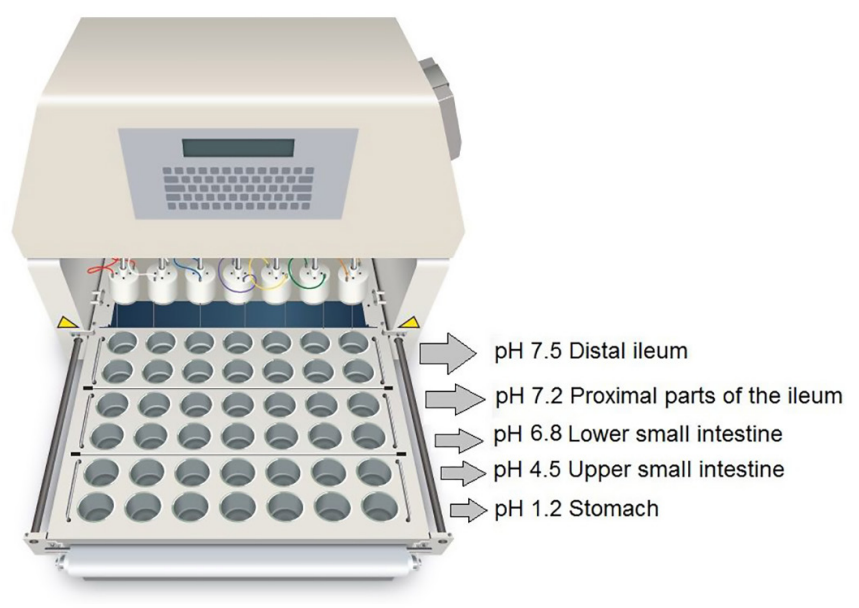

FIGURE 2 - Schematic representation of apparatus 3 and its six lines of vessels, each containing a dissolution medium with a different $\mathrm{pH}$ value, by way of example, simulating the passage of the product through the gastrointestinal (GI) tract (Borst, Ugwu, Beckett, 1997).

Figures 3 and 4 present hypothetical dissolution profile of an extended-release formulation in USP apparatuses 1 and 3, respectively.

In the hypothetical cases listed early, it can be observed that the formulation releases the drug in a similar fashion to USP apparatuses 1 (pH 6.8) and 3 (pH gradient). However, with the results obtained in USP apparatus 3, it is possible to assess that the product should not present any dose-dumping issues, since, under all $\mathrm{pH}$ conditions, no drug delivery peaks are registered, which indicates that the formulation is capable of resisting the $\mathrm{pH}$ gradient to which it will be subjected during its passage through the GI tract. This information is of great use to the formulator.

USP Apparatus 3 also has an important application in the assessment of gastro-resistant formulations, considering the possibility of change in the dissolution 


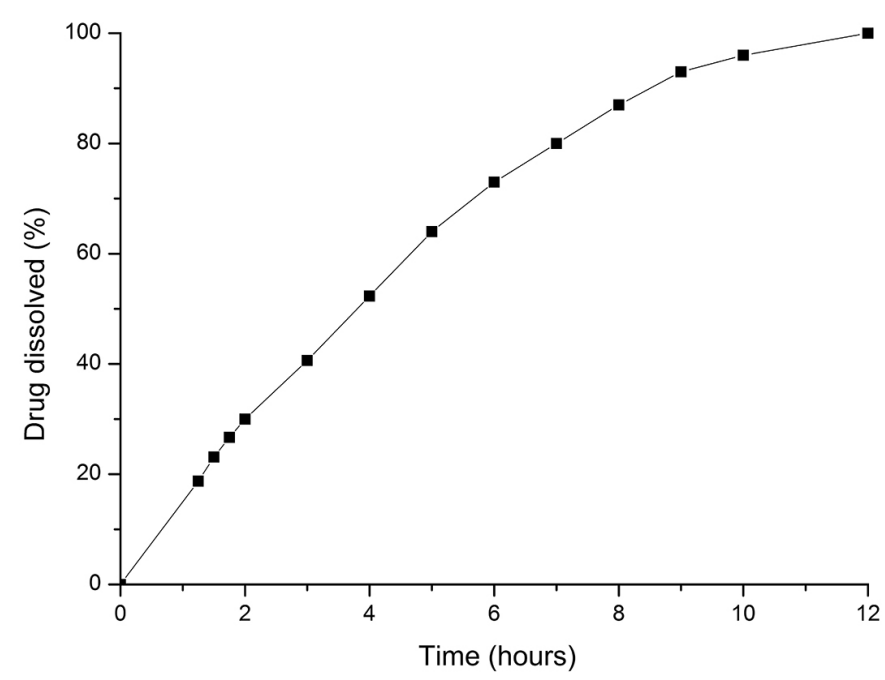

FIGURE 3 - Dissolution profile representing a hypothetical extended-release formulation using USP apparatus 1 in a $\mathrm{pH}$ 6.8 buffer solution.

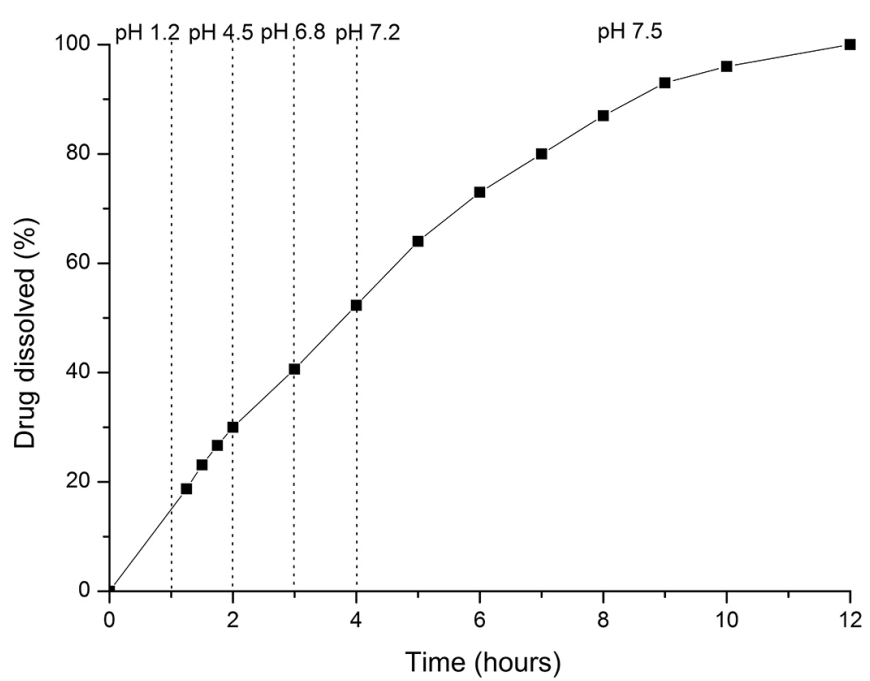

FIGURE 4 - Dissolution profile representing a hypothetical extended-release formulation using apparatus 3 under different $\mathrm{pH}$ conditions $(1.2,4.5,6.8,7.2$ and 7.5).

medium during the assay. The dissolution profiles of a hypothetical gastro-resistant formulation in USP apparatuses 1 and 3 can be found in Figures 5 and 6, respectively.

From the observation of the hypothetical dissolution profiles in the figures above, it is possible to state that the use of USP apparatus 3 in the development of colontargeted and enteric-release dosage forms is especially significant (Yang, 2008). In the conditions of USP apparatus 1 (Figure 5), it is not possible to assess the capacity of the formulation to resist the acid medium of the stomach. However, considering USP apparatus 3, it is perfectly feasible to execute a much more detailed

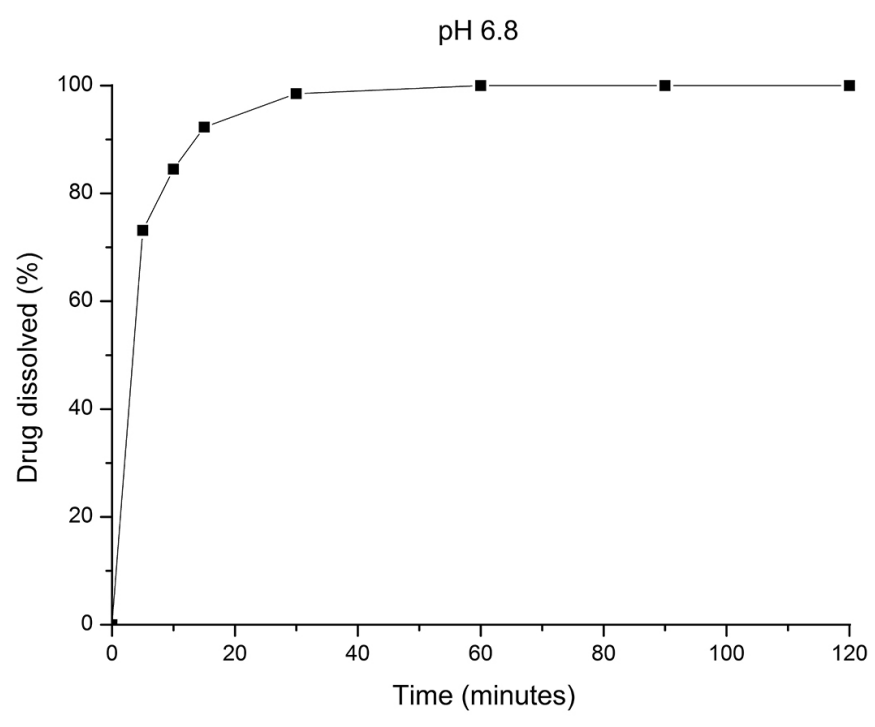

FIGURE 5 - Hypothetical dissolution profile of a gastro-resistant formulation using USP apparatus 1 in a pH 6.8 buffer.

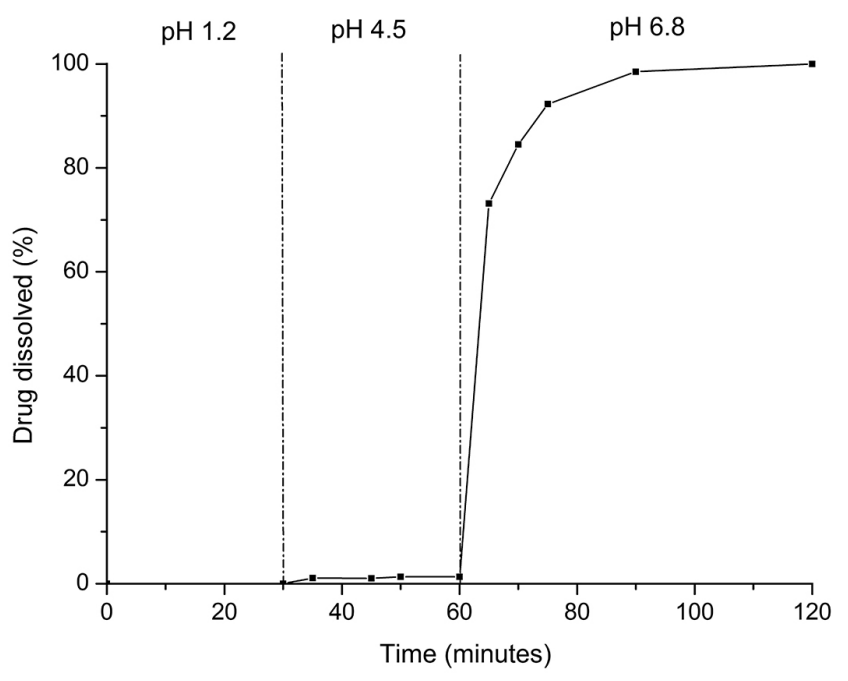

FIGURE 6 - Hypothetical dissolution profile of a gastro-resistant formulation using USP apparatus 3 in three different media $(\mathrm{pH}$ $1.2,4.5$ and 6.8$)$.

description of the drug delivery in this type of formulation, thus establishing the $\mathrm{pH}$ in which the dissolution actually takes place.

\section{SIMULATION OF FASTED AND FED STATES}

Besides its use in the development of dosage forms, the dissolution test has become an important tool in assessing the performance of formulations under conditions very close to those encountered in the human gastrointestinal (GI) tract. However, in order to achieve this, the assays must be outlined and executed in conditions different from those usually employed 
and described in Pharmacopoeias, both in terms of the equipment used and in the composition of dissolution media, such that they simulate the nutritional state of the patient (Klein, 2010).

Accordingly, Dressman et al. (1998) suggest alterations to the composition of dissolution media so that they can correspond better to fasted and fed states. This is the beginning of the use of the so-called biorelevant media; i.e., dissolution media with compositions that are similar to the conditions encountered in the GI tract. Factors such as $\mathrm{pH}$, buffer capacity, presence of surfactants and enzymes, volume of fluid present in the GI tract and hydrodynamics, must be taken into account when it comes to a biorelevant dissolution medium.

Thus, besides the use of biorelevant media, the simulation of the fasted and fed states requires the use of conditions that reflect the hydrodynamics of the GI tract as closely as possible. Accordingly, the reciprocating cylinder apparatus is beneficial for this type of assessment. If simulation of the fed state is desired, agitation of the product may be executed for 1 hour in the first line of vessels. In order to mimic the fasted state, this time may be increased to 4 hours, followed by 1 hour of agitation in the second line. In both cases, the appropriate agitation period in other lines must be selected depending on the type of product to be analyzed, compared to the drug delivery time, which may be from 8 to 24 hours (Yang, 2008; Asare-Addo et al., 2011).

Another important issue involves the mechanical forces and the degree of agitation to which the product is exposed in the GI tract, in the form of intestinal motility and pressure on the stomach, duodenum and jejunum. It is particularly critical in the case of dosage forms that are subject to erosion, such as hydrophilic matrices (Kavanagh, Corrigan, 2004; Missaghi, Fassihi, 2005; Asare-Addo et al., 2010). Although it may be difficult to select the agitation intensity that best mimics in vivo conditions, it is common to use 5-15 dips per minute (dpm) to simulate the fasted state and 30-40 dpm for the fed state, thus representing the greater turbulence within the stomach (Borst, Ugwu, Beckett, 1997). Furthermore, inert spheres of varying densities may be added in order to simulate interaction with solid food particles in movement (Missaghi, Fassihi, 2005).

With regards to the composition of the dissolution media, several approaches may be used to simulate the presence of foodstuffs in the GI tract. One example is immersion of the dosage form in peanut oil, and stirring it for 2 hours at $37^{\circ} \mathrm{C}$ and then begin the assay using dissolution media that reflect the different $\mathrm{pH}$ values and ionic strength present in the GI tract in the fasted state.
Another possibility would be to eliminate prior treatment of the sample and then add peanut oil to the dissolution medium of the first lines of vessels. The other conditions for undertaking the test are similar to these described previously (Mu, Tobyn, Staniforth, 2003).

Besides these approaches, biorelevant dissolution media constitute a very interesting tool, because they are more capable of simulating drug delivery throughout the GI tract, in both the fasted and fed state, and they are now used very frequently (Wang, Fotaki, Mao, 2009; Jantratid, Dressman, 2009).

Besides $\mathrm{pH}$ and volume, these types of dissolution media take into account other characteristics such as osmotic concentration, the presence of enzymes and surface tension, as a means of best mimicking especially the conditions in the small intestine, including the presence of bile salts (Witzleb et al., 2012; Zoeller, Dressman, Klein, 2012).

\section{APPLICATIONS OF USP APPARATUS 3 FOR IMMEDIATE-RELEASE DOSAGE FORMS}

Although it has been conceived for dissolution tests involving extended-release dosage forms, the reciprocating cylinder apparatus has a significant potential for assessing immediate-release dosage forms.

One advantage of its use in this case is the significantly reduced quantity of water and reagents required for the preparation of the media, considering the volume of the dissolution vessels, compared to the basket and paddle methods (Yu, Wang, Hussain, 2002).

However, a smaller medium volume may make the equipment unfeasible for products containing poorlysoluble drugs, unless measures are taken to ensure sink conditions. Examples of possibilities are the use of larger vessels, up to $1,000 \mathrm{~mL}$ and the addition of surfactants to the dissolution medium (Yu, Wang, Hussain, 2002). In this latter case, the use of an anti-foam agent may be necessary, since the movement of the cylinders may generate a large amount of foam (Jorgensen, Bhagwat, 1998).

It is important to emphasize that, contrary to modified-release dosage forms, the use of several lines of vessels containing the dissolution medium may not be applied to immediate-release products. This is because the dosage form disintegrates; generating fragments that may come out of the internal cylinder and pass through the screen of the lower cover. The drug present in these fragments may still be encountered in its undissolved state when the last samples are collected, which occurs shortly before the metallic rods move the internal cylinders to the next line of vessels. Accordingly, results 
will be compromised due to the loss of undissolved drug throughout the test.

USP Apparatus 3 also may be used as for chewable tablets, with the use of glass spheres during the test in order to increase the agitation speed (Siewert et al., 2003).

\section{ADVANTAGES OVER TRADITIONAL ME- THODS}

The basket and paddle apparatus are well established and broadly used for the assessment of in vitro dissolution of solid oral dosage forms. Despite the great popularity of these methods, they present some disadvantages (Hanson; Gray, 2004).

With regards to USP apparatus 1, the results obtained may suffer interference and obstruction of the basket screen, which may occur during the assessment of matrix formulations that are subject to swelling. Furthermore, drug particles may be expelled and float to the surface of the dissolution medium (lower density) or settle at the bottom of the vessel (higher density) (Borst, Ugwu, Beckett, 1997; Jorgensen, Bhagwat, 1998).

With regards to USP apparatus 2, the phenomenon called coning may be observed. It is characterized by the formation of a cone of powder/granules at the bottom of the vessel when the medium is being stirred, due to the poor agitation capacity of the system, especially when it is operated at $50 \mathrm{rpm}$. The particles in the cone are subjected to a lower agitation speed, which may reduce dissolution and affect the variability of the results (Borst, Ugwu, Beckett, 1997; Yu, Wang, Hussain, 2002; Krämer, Grady, Gajendran, 2005).

Due to the design and reciprocal action of USP apparatus 3, none of the aforementioned problems have been observed. Furthermore, the results are not influenced by the presence of bubbles in the dissolution medium, making degasification of the medium unnecessary, thus representing huge time savings and greater practicality. Accordingly, the system is considered to have superior hydrodynamics compared to the basket and paddle apparatus (Borst, Ugwu, Beckett, 1997; Jorgensen, Bhagwat, 1998).

Another significant advantage of the reciprocating cylinder apparatus is the consumption of dissolution media, since tests can be conducted using a volume of up to $300 \mathrm{~mL}$. Furthermore, the minimum operational volume for this apparatus is around $150 \mathrm{~mL}$. This is an advantage compared to USP apparatuses 1 and 2, when it comes to their use in the dissolution of products that require a smaller volume of dissolution medium (Cryst, 2009).
Furthermore, the reciprocating cylinder apparatus enables a better assessment of the dosage form under different $\mathrm{pH}$ conditions during the test. This type of evaluation, when executed in USP apparatuses 1 or 2 , requires a change in the dissolution medium that is difficult to conduct. Accordingly, USP apparatus 3 may be used for a more faithful assessment of release mechanisms under physiological conditions (Brown, 2005).

USP apparatus 3 can be used to evaluate drug release from hydroxypropylmethyl cellulose (HPMC) extendedrelease tablets. Considering that erosion is the dominant release mechanism from HPMC tablets containing poorlysoluble drugs and that the presence of food components in gastrointestinal tract have a critical effect on tablet disintegration, different dip rates from this apparatus in the evaluation of these dosage forms could be related to food effects on HPMC erosion (Asare-Addo et al., 2010).

\section{FINAL CONSIDERATIONS}

USP apparatus 3 has important advantages over the basket and paddle apparatuses in the assessment of in vitro dissolution characteristics of modified-release dosage forms. As the apparatus is very versatile, its application is not restricted to extended-release products, and it may also be used for other solid oral dosage forms, such as immediate-release forms, and it is a useful tool in the simulation of fasted and fed states, using biorelevant media.

\section{REFERENCES}

AMIDON, G.L.; LENNERNÄS, H.; SHAH, V.P.; CRISON, J.R. A theoretical basis for a biopharmaceutic drug classification: The correlation of in vitro drug product dissolution and in vivo bioavailability. Pharm. Res., v.12, n.3, p.413-420, 1995.

ASARE-ADDO, K.; LEVINA, M.; RAJABI-SIAHBOOMI, A.R.; NOKHODCHI, A. Effect of ionic strength and $\mathrm{pH}$ of dissolution media on theophylline release from hypromellose matrix tablets - Apparatus USP III, simulated fasted and fed conditions. Carbohyd. Polym., v.86, n.1, p.85-93, 2011.

ASARE-ADDO, K.; LEVINA, M.; RAJABI-SIAHBOOMI, A.R.; NOKHODCHI, A. Study of dissolution hydrodynamic conditions versus drug release from hypromellose matrices: The influence of agitation sequence. Colloid. Surface B., v.81, n.2, p.452-460, 2010. 
AZARMI, S.; ROA, W.; LÖBENBERG, R. Current perspectives in dissolution testing of conventional and novel dosage forms. Int. J. Pharm., v.328, n.1, p.12-21, 2007.

BORST, I.; UGWU, S.; BECKETT, A.H. New and extended applications for USP drug release apparatus 3. Dissolut. Technol., v.4, n.1, p.11-15, 1997.

BROWN, C. Dissolution method development: an industry perspective. In: DRESSMAN, J.; KRÄMER, J. (Eds.). Pharmaceutical dissolution testing. Boca Raton: Taylor \& Francis, 2005. 429 p.

CRYST, G.B. 2009 Trends in small-volume dissolution apparatus for low-dose compounds. Dissolut. Technol., v.16, n.1, p.19-22, 2009.

DOKOUMETZIDIS, A.; MACHERAS, p.A century of dissolution research: From Noyes and Whitney to the biopharmaceutics classification system. Int. J. Pharm., v.321, n.1, p.1-11, 2006.

DRESSMAN, J.; AMIDON, G.L.; REPPAS, C.; SHAH, V.P. Dissolution testing as a prognostic tool for oral drug absorption: immediate release dosage forms. Pharm. Res., v.15, n.1, p.11-22, 1998.

EMAMI, J. In vitro - In vivo Correlation: From Theory to Applications. J. Pharm. Pharm. Sci., v.9, n.2, p.169-189, 2006.

FOOD AND DRUG ADMINISTRATION. FDA. Waiver of in vivo bioavailability and bioequivalence studies for immediate-release solid oral dosage forms based on a biopharmaceutics classification system: Guidance for Industry. Washington, DC,: Department of Health and Human Services. Food and Drug Administration, Center for Drug Evaluation and Research (CDER), U. S. Government Printing Office: 2000.

HANSON, R.; GRAY, v.Handbook of dissolution testing. 3. ed. Hockessin, DE: Dissolution Technologies, 2004. 199 p.

JANTRATID, E.; DRESSMAN, J. Biorelevant dissolution media simulating the proximal human gastrointestinal tract: an update. Dissolut. Technol., v.16, n.3, p.21-25, 2009.

JORGENSEN, E.D.; BHAGWAT, D. Development of dissolution tests for oral extended-release products. Pharm. Sci. Technol. To., v.1, n.3, p.128-135, 1998.
KAVANAGH, N.; CORRIGAN, O. I. Swelling and erosion properties of hydroxypropylmethylcellulose (hypromellose) matrices - influence of agitation rate and dissolution medium composition. Int. J. Pharm., v.279, n.1-2, p.141152, 2004.

KLEIN, S. The use of biorelevant dissolution media to forecast the in vivo performance of a drug. AAPS J., v.12, n.3, p.397406, 2010.

KLEIN, S.; WUNDERLICH, M.; DRESSMAN, J.; STIPPLER, E. Development of dissolution tests on the basis of gastrointestinal physiology. In: DRESSMAN, J.; KRÄMER, J. (Eds.). Pharmaceutical dissolution testing. Boca Raton: Taylor \& Francis, 2005. 429 p.

KRÄMER, J.; GRADY, L.T.; GAJENDRAN, J. Historical development of dissolution testing. In: DRESSMAN, J.; KRÄMER, J. (Eds.). Pharmaceutical dissolution testing. Boca Raton: Taylor \& Francis, 2005. 429 p.

KUMAR, M.N.V.R.; DOMB, A.J. Controlled drug delivery. In: WNEK, G.E.; BOWLIN, G.L. Encyclopedia of biomaterials and biomedical engineering. New York: Marcel Dekker, 2004. chap.84.

MISSAGHI, S.; FASSIHI, R. Release characterization of dimenhydrinate from an eroding and swelling matrix: selection of appropriate dissolution apparatus. Int. J. Pharm., v.293, n.1-2, p.35-42, 2005.

MU, X.; TOBYN, M.J.; STANIFORTH, J. N. Development and evaluation of bio- dissolution systems capable of detecting the food effect on a polysaccharide-based matrix system. $J$. Control. Release, v.93, n.3, p.309-318, 2003.

PEZZINI, B.R.; FERRAZ, H.G. Bio-Dis and the paddle dissolution apparatuses applied to the release characterization of ketoprofen from hypromellose matrices. AAPS PharmSciTech., v.10, n.3., p.763-771, 2009.

RIBEIRO, L.; FERREIRA, D.C.; VEIGA, F.J.B. In vitro controlled release of vinpocetine-cyclodextrin-tartaric acid multicomponent complexes from HPMC swellable tablets. J. Control. Release, v.103, n.2, p.325-339, 2005.

SIEWERT, M.; DRESSMANN, J.; BROWN, C.; SHAH, v.FIP/ AAPS Guidelines for dissolution/ in vitro release testing of novel/special dosage forms. Dissolut. Technol., v.10, n.1, p.6-15, 2003. 
WANG, Q.; FOTAKI, N.; MAO, Y. Biorelevant dissolution: methodology and application in drug development. Dissolut. Technol., v.16, n.3, p.6-12, 2009.

WITZLEB, R.; MÜLLERTZ, A; KANIKANTI, V.-R.; HAMANN, H.-J.; KLEINEBUDDE, p.Dissolution of solid lipid extrudates in biorelevant media. Int. J. Pharm., v.422, n.1-2, p.116-124, 2012.

YANG, L. Biorelevant dissolution testing of colon-specific delivery systems activated by colonic microflora. J. Control. Release., v.125, n.2, p.77-86, 2008.
YU, L.X.; WANG, J.T.; HUSSAIN, A.S. Evaluation of USP apparatus 3 for dissolution testing of immediate-release products. AAPS PharmSci., v.4, n.1, p.1-5, 2002.

ZOELLER, T.; DRESSMAN, J.B.; KLEIN, S. Application of a ternary HP- $\beta$-CD-complex approach to improve the dissolution performance of a poorly soluble weak acid under biorelevant conditions. Int. J. Pharm., v.430, n.1-2, p.176-183, 2012.

Received for publication on $07^{\text {th }}$ January 2015 Accepted for publication on $04^{\text {th }}$ November 2014 